\title{
Growth differentiation factor-15 upregulates interleukin-6 to promote tumorigenesis of prostate carcinoma PC-3 cells
}

\author{
Ke-Hung Tsui ${ }^{1,2 *}$, Ying-Ling Chang ${ }^{3 *}$, Tsui-Hsia Feng ${ }^{4}$, Li-Chuan Chung ${ }^{5}$, Tzu-Yi Lee ${ }^{5}$, \\ Phei-Lang Chang ${ }^{1,2}$ and Horng-Heng Juang ${ }^{2,5}$ \\ ${ }^{1}$ Department of Urology and ${ }^{2}$ Bioinformation Center, Chang Gung Memorial Hospital, Kwei-Shan, Tao-Yuan, Taiwan \\ ${ }^{3}$ School of Traditional Chinese Medicine, ${ }^{4}$ School of Nursing and ${ }^{5}$ Department of Anatomy, College of Medicine, Chang Gung University, 259 Wen-Hua 1st Road, \\ Kwei-Shan, Tao-Yuan 333, Taiwan \\ (Correspondence should be addressed to H-H Juang at Department of Anatomy, College of Medicine, Chang Gung University; Email: hhj143@mail.cgu.edu.tw) \\ *(K-H Tsui and Y-L Chang contributed equally to this work)
}

\begin{abstract}
Growth differentiation factor-15 (GDF15), a member of the transforming growth factor- $\beta$ superfamily, is associated with human cancer progress. We evaluated the role GDF15 plays in tumorigenesis of prostate carcinoma PC-3 cells. Results from real-time RT-PCR and ELISA revealed that expression of GDF15 was approximately threefold higher in LNCaP cells than in PC-3 cells. Other prostate cell lines (PZ-HPV-7, CA-HPV-10, and DU145 cells) expressed extremely low levels of GDF15. Stable overexpression of GDF15 in PC-3 cells enhanced the degree of cell proliferation and invasion as shown in the ${ }^{3} \mathrm{H}$-thymidine incorporation assay and in the Matrigel invasion assay respectively. Soft agar assays and xenograft animal studies indicated that overexpression of GDF15 in PC-3 cells increased tumorigenesis in vitro and in vivo. Results from RT-PCR, immunoblot, and reporter assays revealed that overexpression of GDF15 resulted in decreased expression of maspin and upregulation of interleukin-6 (IL6), matriptase, and N-myc downstream-regulated gene 1 (NDRG1) expression. Further studies revealed that overexpression of IL6 enhanced GDF15 expression in LNCaP cells while knockdown of IL6 blocked the expression of GDF15 in PC-3 cells, suggesting that expression of GDF15 is upregulated by IL6. This study demonstrated that expression of GDF15 induces cell proliferation, invasion, and tumorigenesis of prostate carcinoma PC-3 cells. The enhancement of tumorigenesis and invasiveness of prostate carcinoma cells that stably overexpress GDF15 may be caused by the dysregulation of maspin, matriptase, and IL6 gene expression. The expression of GDF15 and IL6 is controlled via a positive feedback loop in PC-3 cells.
\end{abstract}

Journal of Molecular Endocrinology (2012) 49, 153-163

\section{Introduction}

Growth differentiation factor-15 (GDF15), isolated from a differential screen for genes, is also known as macrophage inhibitory cytokine 1 , placental bone morphogenetic protein, placental transforming growth factor- $\beta$ (TGF- $\beta$ ), nonsteroidal anti-inflammatory drugactivated gene-1, and prostate differentiation factor (Bootcov et al. 1997, Hromas et al. 1997, Paralkar et al. 1998). GDF15 is a secretory dimeric protein that bears the structural characteristics of cytokines in the TGF- $\beta$ superfamily (Welsh et al. 2003, Bauskin et al. 2005). The GDF15 gene is abundantly expressed in placenta and expressed in relatively low levels in prostate, liver, kidney, pancreas, and fetal brain (Paralkar et al. 1998). The major function of GDF15 is not completely understood. Studies have shown that GDF15 is involved in the inhibition of cell growth, induction of apoptosis, and enhancement of cancer invasiveness in different cancer cell lines (Baek et al. 2006, 2009, Kadara et al. 2006, Lambert et al. 2006, Golkar et al. 2007).
Results from studies on GDF15 expression in prostate cancer are somewhat controversial. GDF15 was found to be overexpressed in prostate intraepithelial neoplasia; however, decreased expression was observed in higher grade cancer (Iczkowski \& Pantazis 2003). Karan et al. (2003) indicated stronger immunohistochemical staining in the areas of adenocarcinoma than in the benign glandular areas of prostate tissues. Another study showed that levels of GDF15 expression were higher in prostate cancer than in normal prostate tissues and were also significantly higher in well-differentiated prostate cancer than in moderately and poorly differentiated adenocarcinomas (Kawahara et al. 2010). Brown et al. (2009) found that increased serum GDF15 concentrations are strongly associated with advancement and progression of prostate cancer. However, relevant in vitro studies have made discrepant findings. Early study showed that upregulation of GDF15 gene expression by vitamin $\mathrm{D}_{3}$ suppresses cell growth of prostate carcinoma LNCaP cells (Lambert et al. 2006). Other studies indicated that GDF15 
induced apoptosis of DU145 cells and attenuated cell invasion in PC-3 cells (Liu et al. 2003, Cheng et al. 2011). Animal studies concluded that GDF15 is involved in anorexia and weight loss, and GDF15 overexpression inhibits tumorigenesis of DU145 and PC-3 cells (Lambert et al. 2006, Johnen et al. 2007, Wang et al. 2012). Paradoxically, in vivo and in vitro studies have indicated that overexpression of GDF15 induced osteolytic bone lesions in DU145 cells, and a progressive increase in secretory GDF15 production correlated with the increase in the metastatic potential of prostate carcinoma PC-3 and LNCaP cells (Wakchoure et al. 2009, Senapati et al. 2010).

The objectives of this study were to determine the expression of GDF15 in human prostate carcinoma cells, to determine the tumorigenesis and invasiveness of PC-3 cells engineered to overexpress GDF15, and to evaluate the mechanisms by which GDF15 induces tumorigenesis in human prostate carcinoma cells.

\section{Materials and methods}

\section{Cell culture and chemicals}

PZ-HPV-7, CA-HPV-10, LNCaP, PC-3, and DU145 cell lines were obtained from the Bioresource Collection and Research Center (BCRC, Taiwan) and were maintained as described previously (Tsui et al. 2012b). FCS was purchased from HyClone (Logan, UT, USA), RPMI 1640 media from Life Technologies, recombinant human GDF15 from PeproTech (Rocky Hill, NJ, USA), doxorubicin from Sigma, and Matrigel from Becton Dickinson Biosciences (Bedford, MA, USA).

\section{Expression vector constructs and stable transfection}

Full-length human GDF15 cDNA (MCG: 4145) and interleukin-6 (ILO) cDNA (MCG: 9215) vectors were purchased from Invitrogen. The human GDF15 expression vector (pcDNA3-GDF15) was constructed by cloning GDF15 cDNA vector after digestion with EcoRI and NotI into the pcDNA3 expression vector (Invitrogen). The GDF15 expression vector was introduced into the PC-3 cells by electroporation as described previously (Tsui et al. 2011a). Cells were maintained in RPMI medium with $10 \%$ FCS and G418 (PAA Laboratories, Linz, Austria) at a final concentration of $800 \mu \mathrm{g} / \mathrm{ml}$. The two selected resistant colonies were examined to evaluate GDF15 expression by RT-PCR, immunoblot assay, and ELISA as described below and designated as PCGDF15-1 and PCGDF15-2 cells. The mock-transfected PC-3 cells (PCDNA) were transfected with controlled pcDNA3 expression vector and were clonally selected in the same manner as the PCGDF15 cells. The human IL6 expression vector was constructed, introduced into LNCaP cells by electroporation, and maintained in RPMI medium with $10 \%$ FCS and Zeocin (Invitrogen) at a final concentration of $100 \mu \mathrm{g} / \mathrm{ml}$ as described previously (Tsui et al. 2011b). The colonies were designated as LN-IL6. The mocktransfected LNCaP cells (LN-DNA) were transfected with the control pcDNA3.1/Zeo expression vector and were selected in the same manner as the LN-IL6 cells. The pSMc2 retroviral vectors containing IL6 short hairpin RNA (shRNA; clone ID: V2HS-111640) and EGFP shRNA (clone ID: RHS1764-9394112) were purchased from Open Biosystems (Huntsville, AL, USA). The IL6 and EGFP knockdown vectors were introduced into PC-3 cells respectively by electroporation and selected by $2 \mu \mathrm{g} / \mathrm{ml}$ puromycin dihydrochloride. The IL6 knockdown PC-3 cells were termed PC-IL6si cells and EGFP knockdown PC-3 cells were termed PCcolsi cells. Cells that expressed IL6 in resistant colonies were evaluated by RT-PCR and ELISA as described below.

\section{siRNA transfection}

GDF15-specific siRNA (sc-39798, Sigma) or nonsense siRNA (sc-37007, Sigma) was transiently transfected into PC-3 cells using Lipofectamine RNAiMAX (Invitrogen) according to the manufacturer's protocol. To determine the effectiveness of siRNAmediated knockdown, immunoblot assay and ELISA, as described below, were used to measure the abundance of GDF15.

\section{Semiquantitative and real-time RT-PCR}

Total RNA was isolated with Trizol reagent and cDNA was synthesized using the superscript III pre-amplification system as described previously (Pang et al. 2009). The GDF15 primers (5'-GGCCAACCAGAGCTGGGAAG-3' and 5'-GCCCGAGAGATACGCAGGT G-3') were used to amplify sequences specific to human GDF15 mRNA. The sequence of primers used to amplify sequences specific to human maspin, N-myc downstream-regulated gene 1 (NDRG1), matriptase, IL6, and $\beta$-actin were previously described (Tsui et al. 2008a, $2011 b, 2012 a)$. After separation by $2 \%$ agarose gel electrophoresis, the PCR products were visualized by ethidium bromide staining. Real-time PCRs (qPCR) were performed using an ABI StepOne Plus Real-Time PCR system (Applied Biosystems) as described previously (Chung et al. 2012). FAM dye-labeled TaqMan MGB probes and PCR primers for human GDF15 (Hs00171132_m1) were purchased from Applied Biosystems. For the internal positive controls, 18S rRNA (18S; Hs03003631_g1) was used with an FAM reporter dye-labeled TaqMan MGB probe. 


\section{Immunoblot assay}

Equal quantities of cell extract were loaded onto a $10 \%$ SDS-polyacrylamide gel and analyzed using the Western lightning plus-ECL detection system (PerkinElmer, Inc., Waltham, MA, USA) as described previously (Tsui et al. 2012a). The blotting membranes were probed with 1:5000 diluted polyclonal matriptase antiserum (IM1014; Calbiochem, Darmstadt, Germany), 1:1000 diluted maspin antiserum (554292; BD Biosciences, Bedford, MA, USA), 1:5000 diluted NDRG1 antiserum (N-19; Santa Cruz Biotechnology), 1:500 diluted GDF15 antiserum (07-217; Upstate Biotechnology, Charlottesville, VA, USA), or 1:1000 diluted anti$\beta$-actin antiserum (C11, Santa Cruz Biotechnology). The intensity of immunoblotting assay was recorded by the Chemi Genius 2 Biolmaging system of (Syngene, Cambridge, UK).

\section{ELISA}

Cells were incubated with $1 \mathrm{ml}$ RPMI 1640 medium with $10 \%$ FCS. Following incubation, the conditioned medium from each well was collected for GDF15 or IL6 assay. The IL6 levels in the conditioned media were measured by an IL6 ELISA as described by the manufacturer (Catalog \#:2107; Bio Scientific Corporation, Austin, TX, USA). The GDF15 levels in the conditioned media or serum samples collected from animal studies were measured using a GDF15 ELISA according to the manufacturer's instructions (Catalog \#: DY957; R\&D Systems, Inc., Minneapolis, MN, USA). The GDF15 and IL6 levels in each sample were adjusted according to the concentrations of protein in the whole cell extract that had been measured using a bicinchoninic acid protein assay kit (Pierce Biotechnology, Rockford, IL, USA).

\section{Cell proliferation assay}

Proliferation of PCDNA and PCGDF15 cells was measured by a ${ }^{3} \mathrm{H}$-thymidine incorporation assay as described previously (Chung et al. 2011). In this assay, $5 \times 10^{4}$ cells were cultured in each well of a six-well plate in RPMI 1640 medium with $10 \%$ FCS. After a required incubation period, $1 \mu \mathrm{Ci} / \mathrm{ml}{ }^{3} \mathrm{H}$-thymidine (PerkinElmer, Boston, MA, USA) was added to each well of a six-well plate. The plate was then incubated at $37^{\circ} \mathrm{C}$ in a humidified $5 \% \mathrm{CO}_{2}$ atmosphere for $4 \mathrm{~h}$. Cells were washed twice with cold PBS and then with cold $5 \%$ TCA. Cells were solubilized by adding $0.5 \mathrm{ml} 0.5 \mathrm{M}$ $\mathrm{NaOH}$. Then, $400 \mu \mathrm{l}$ of the solubilized cell solution was mixed with $4 \mathrm{ml}$ scintillation cocktail and counted with a Liquid Scintillation Analyzer (Packard BioScience, Downers Grove, IL, USA).

\section{Matrigel invasion assay}

The Matrigel invasion assay was performed as described previously (Tsui et al. 2012b). Briefly, $500 \mu$ l RPMI 1640 media with $10 \%$ FCS were added to the lower chamber of the 24-well plate. Culture was performed with $200 \mu \mathrm{l}$ cells in serum-free RPMI 1640 medium in the upper well at a density of $1 \times 10^{5}$ cells $/ \mathrm{ml}$. The plates were placed in an incubator with $5 \% \mathrm{CO}_{2}$ at $37^{\circ} \mathrm{C}$ for $24 \mathrm{~h}$. Cells that migrated to the Matrigel-coated transmembrane were fixed in $4 \%$ paraformaldehyde and then stained with $0 \cdot 1 \%$ crystal violet solution for $30 \mathrm{~min}$. The results were recorded by a digital camera connected to an inverted microscope (IX71, Olympus, Tokyo, Japan). The membrane was soaked in $10 \%$ acetate acid and agitated at $37^{\circ} \mathrm{C}$ for $1 \mathrm{~h}$. The acetate acid solution was then read by a spectrophotometer at 635 nm (DU640; Beckman, Fullerton, CA, USA).

\section{Soft agar cloning assay}

Approximately 10000 PCDNA and PCGDF15-2 cells were suspended in $2 \mathrm{ml}$ of $0.4 \%$ agar (Difco Agar Noble; BD Biosciences) in RPMI 1640 medium and plated on top of $1 \mathrm{ml}$ of $0 \cdot 8 \%$ agar in RPMI 1640 medium in a six-well plate. Plates were incubated for 3 weeks at $37^{\circ} \mathrm{C}$ and each well was fed with two to three drops of complete growth medium every 2-3 days. Cell colonies were visualized by staining with $0.5 \mathrm{ml}$ p-iodonitrotetrazolium violet ( $1 \mathrm{mg} / \mathrm{ml}$; Sigma).

\section{Xenograft animal study}

The studies were performed in accordance with the Guide for Laboratory Animal Facilities and Care (Council of Agriculture Executive, Taiwan) and approved by the Chang Gung University Animal Research Committee (IACUC approval NO: CGU08-074). Male nude mice (BALB/cAnN-Foxn1, 4 weeks old) were purchased from the animal center of the National Science Council in Taiwan. The mice were anesthetized i.p. with $50 \mu \mathrm{l} / \mathrm{kg}$ of body weight of ketamine $(100 \mu \mathrm{g} / \mathrm{ml})-x y l a z i n e ~(10 \mu \mathrm{g} / \mathrm{ml})$. Cells $\left(1 \times 10^{6} / 100 \mu \mathrm{l}\right)$ were injected subcutaneously on one side of the lateral back wall close to the shoulder of each mouse. Growth of the xenograft was measured by vernier calipers every 5 days. Tumor volume was calculated with the following formula: Volume $=\pi / 6 \times$ larger diameter $\times(\text { smaller diameter })^{2}$ (Tsui et al. 2012b).

\section{Reporter vector constructs and transient gene expression assay}

The human IL6 reporter vector, maspin reporter vector, and NDRG1 reporter vector were constructed as 
previously described (Tsui et al. 2008b, 2012a). A $6.5 \mathrm{kbp}$ DNA fragment was subtracted from a BAC clone (RP11-679I18; Invitrogen) and cloned into the pGEM-3 vector (Promega BioScience) with the BamH1 cutting site. The DNA fragment containing the promoter of the $5^{\prime}$-flanking region of the matriptase gene $(-3468$ to -9$)$ was synthesized with matriptasepromoterR (5'-CCATGGCTCACACTCCGGCCCGGCCGGCCCA- $3^{\prime}$ ) and T7 primers (Promega BioScience) by PCR and cloned into the pGL3-Basic vector at the KpnI and NcoI cutting sites. Proper ligation and orientation of reporter vectors were confirmed by extensive restriction mapping and sequencing. Cells were plated onto 24-well plates at $1 \times 10^{4}$ cells/well 1 day before transfection. They were then transiently transfected using TransFast transfection reagent $(0 \cdot 6 \mu \mathrm{g} /$ well; Promega Biosciences) with $1 \mu \mathrm{g} /$ well of reporter vector and $0.5 \mu \mathrm{g} /$ well of pCMVSPORT $\beta \mathrm{Gal}$ (Invitrogen) as described previously (Chung et al. 2011). Luciferase activity was determined in relative light units using a LumiCount Luminometer (Packard Bioscience, Meriden, CT, USA) and adjusted according to the $\beta$-GAL enzymatic activity.

\section{Statistical analysis}

Results are expressed as mean \pm s.E.M. of at least three independent replications of each experiment. Statistical significance was determined using the one-way ANOVA and Student's $t$-test and using the SigmaStat program for Windows, version 2.03 (SPSS, Inc.).

\section{Results}

GDF15 expression in prostate carcinoma cells was assessed using RT-PCR (Fig. 1A). LNCaP cells had the highest expression of GDF15 of any cells used in this study. Results of RT-qPCR (Fig. 1B) indicated that the quantitative level of GDF15 mRNA was threefold higher in LNCaP cells than in PC-3 cells. Other cell lines used in this study, namely HPV-7-PZ, HPV-10-CA, and DU145, expressed extremely low levels of GDF15. Similar results were obtained by ELISA (Fig. 1C).

The human GDF15 cDNA was stably transfected in the prostate carcinoma PC-3 cells to evaluate the function of native GDF15 on cell proliferation and invasion. The results of immunoblot assay of GDF15 for the whole-cell extract revealed a major band at $35-37 \mathrm{kDa}$, which represented the precleavage form of GDF15. Results of immunoblot assay (Fig. 2A), RT-qPCR (Fig. 2B), and ELISA (Fig. 2C) confirmed that GDF15 was overexpressed in two PC-3 cell lines that stably overexpressed GDF15 (PCGDF15-1 and PCGDF15-2). Results from the ${ }^{3} \mathrm{H}$-thymidine incorporation assay revealed that

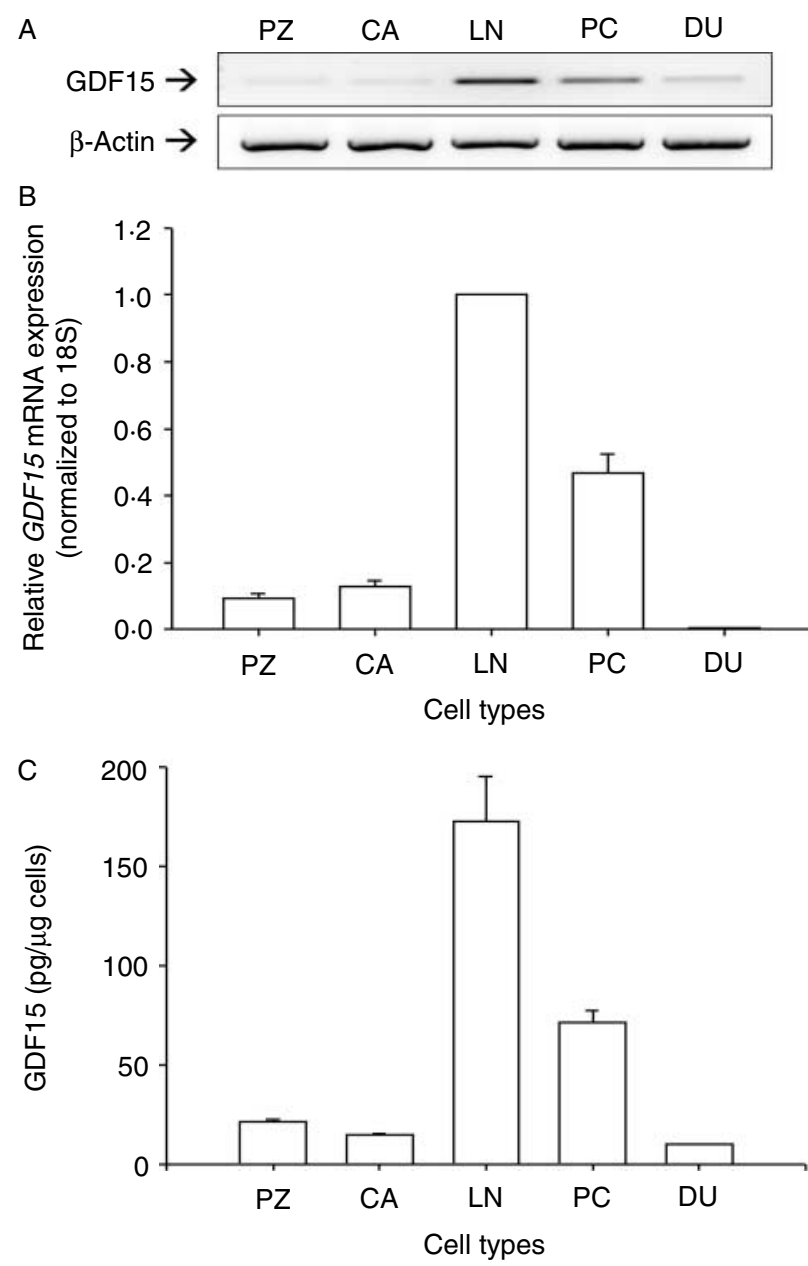

Figure 1 GDF15 expression in human prostate carcinoma cells. Total RNA from cells was extracted for RT-PCR (A) and RT-qPCR (B) assays to determine GDF15 gene expression. The GDF15 mRNA levels of LNCaP cells were set at 1. (C) Conditional media were collected for ELISA to determine GDF15 secretion in different prostate cell lines (PZ: PZ-HPV-7; CA: CA-HPV-10; LN: LNCaP; PC: PC-3; DU: DU145). Data are presented as mean ( \pm s.E.M., $n=6)$ of the GDF15 levels.

GDF15-transfected cells (PCGDF15-1 and PCGDF15-2) increased $4 \cdot 75$ - and $5 \cdot 79$-fold respectively in cell numbers, but mock-transfected PC-3 cells (PCDNA) only increased 3.94-fold in cell numbers after 5-day incubation, indicating that stable overexpression of GDF15 in PC-3 cells enhanced cell proliferation (Fig. 2D).

Results of the in vitro Matrigel invasion assay indicated that the invasive ability of PC-3 cells that overexpressed GDF15 was approximately twofold higher than that of mock-transfected PC-3 cells (Fig. 3A). PC-3 cells that overexpressed GDF15 (PCGDF15-2) increased approximately threefold the ability to grow in soft agar in comparison with mocktransfected PC-3 (PCDNA) cells (Fig. 3B). The effect of 

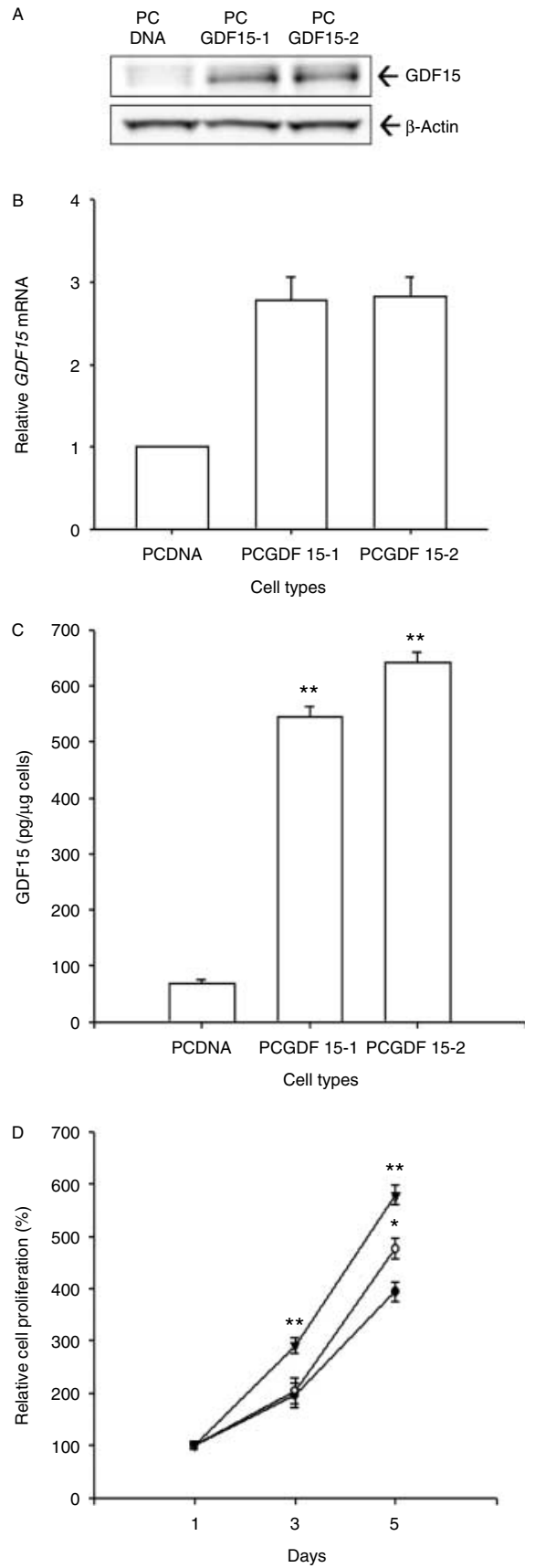

Figure 2 Stable overexpression of GDF15 enhances in vitro cell proliferation of PC-3 cells. (A) Cell extracts were used in the immunoblot assay for determination of GDF15 expression. (B) The expression of GDF15 in PC-3 cells was determined by RT-qPCR after stable transfection of the GDF15 expression vector. (C) Conditional media were collected for ELISA determination of GDF15 expression. Data are expressed as mean ( + S.E.M.; $n=6$ ) of the GDF15 levels. (D) Cell proliferation of mocktransfected PC-3 cells (PCDNA; black circle) and of GDF15 transfected PC-3 cells (PCGDF15-1, white circle; PCGDF15-2, black triangle) was determined by ${ }^{3} \mathrm{H}$-thymidine incorporation. Each point on the curve represents the mean percentage \pm S.E.M. $(n=6)$ of that on day $1\left({ }^{*} P<0.05,{ }^{\star *} P<0.01\right)$.
GDF15 on the growth of tumors in vivo was evaluated using xenografts in nude mice. PCGDF15-2 and PCDNA cells were injected subcutaneously onto the back of the shoulder of athymic nude mice. The mocktransfected PC-3 cell (PCDNA)-generated tumors grew slower than PC-3 cells that overexpressed GDF15 (PCGDF15-2). After 57 days of growth, tumors derived from PCDNA cells were only $\sim 50 \%$ of the size of tumor derived from PCGDF15-2 cells (Fig. 3C). These results were similar to those obtained from in vitro soft agar assays, suggesting that GDF15 enhances tumorigenic activity in prostate carcinoma cells in vivo. ELISA assay of serum samples, which were collected from experimental animals by cardiocentesis, revealed that levels of GDF15 in the circulation were threefold higher in animals that have been injected with PCGDF15-2 cell than in animals that have been injected with PCDNA cells (Fig. 3D).

In order to evaluate the mechanisms involved in the effect of GDF15 on cell proliferation and metastasis, we measured differences in the gene expression of matriptase, maspin, NDRG1, and IL6 between PCDNA and PCGDF15-2 cells. Results of RT-PCR (Fig. 4A) and immunoblot assays (Fig. 4B) revealed that stable overexpression of GDF15 in PC-3 cells enhanced matriptase, NDRG1, and IL6 gene expression but blocked maspin gene expression. Results of the transient gene expression assays also indicated that overexpression of GDF15 enhanced matriptase (Fig. 4C) and NDRG1 (Fig. 4D) promoter activity and attenuated the promoter activity of the maspin gene (Fig. 4E). The ELISA assays revealed that levels of IL6 secretion of PC-3 cells were about twofold higher in PC3 cells (PCGDF15-2) that stably overexpressed GDF15 than in mock-transfected (PCDNA) cells (Fig. 4F). Luciferase activity in PC-3 cells increased in a dosedependent manner after transient cotransfection of the IL6 reporter vector with different concentrations of GDF15 expression vector (Fig. 4G).

To further investigate the function of GDF15 on cell proliferation and invasion, GDF15 was transiently knocked down using siRNA in PC-3 cells. Both the expression levels of GDF15 in GDF15 knockdown PC-3 (PC-GDF15si) cells and mock knockdown (PC-COLsi) cells were determined by immunoblot assay and ELISA. Results of immunoblot assay (Fig. 5A) and ELISA (Fig. 5B) indicated that expression of GDF15 was blocked in GDF15 knockdown PC-3 (PC-GDF15si) cells. Results of immunoblot assays also found that transient knockdown of GDF15 in PC-3 cells augmented maspin protein expression but blocked matriptase and NDRG1 protein expression (Fig. 5A). Moreover, $38.6 \%$ of IL6 secretion was blocked as GDF15 was transiently knocked down in PC-3 cells (Fig. 5B). Results from ${ }^{3} \mathrm{H}$-thymidine incorporation assays revealed that GDF15 knockdown PC-3 cells increased 


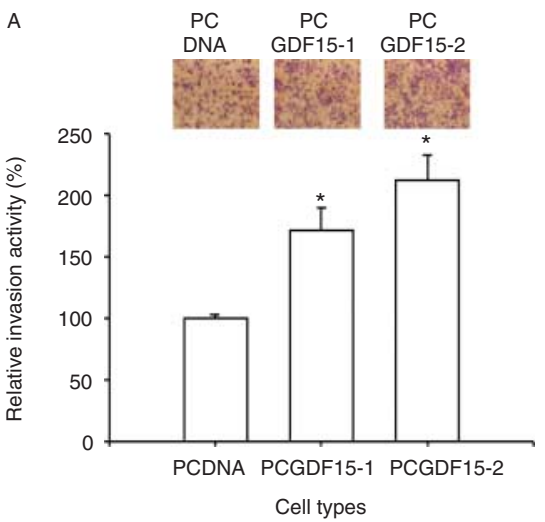

B
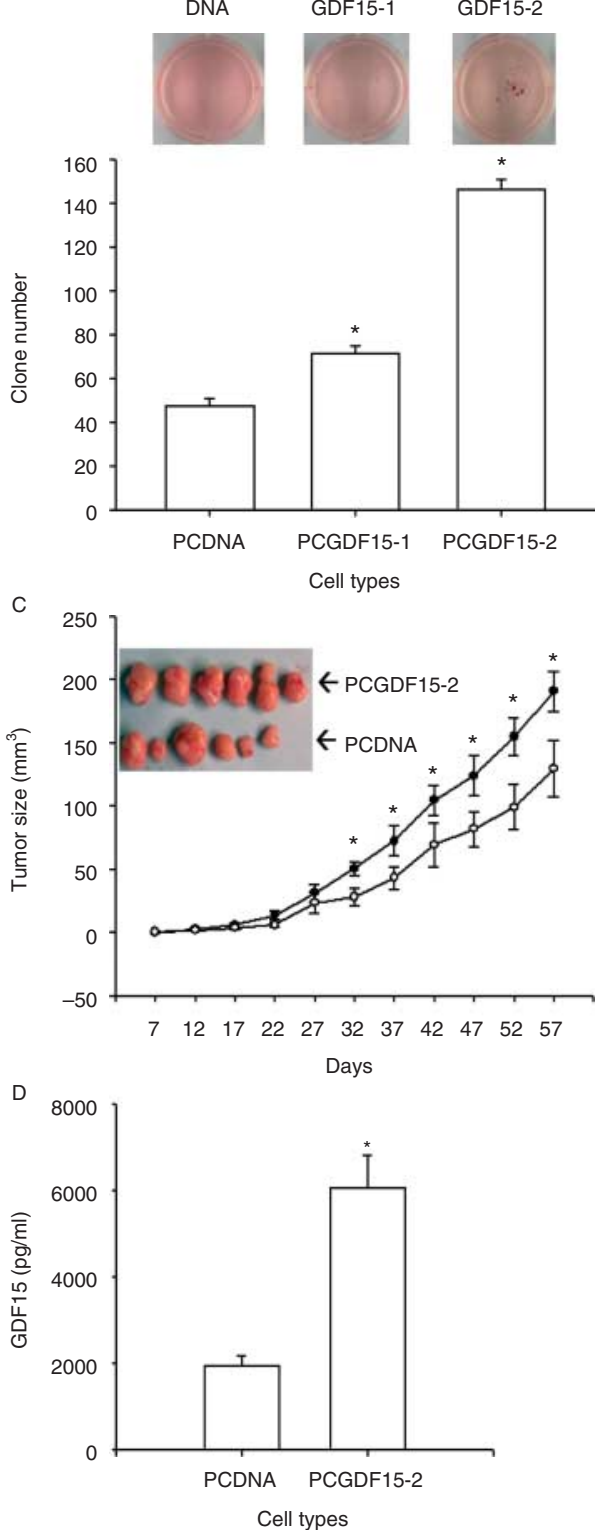

only 2.06-fold in cell numbers but the mock-transfected PC-3 cells (PC-COLsi) increased 3·61-fold in cell numbers after 5 days of incubation, suggesting that transient knockdown GDF15 in PC-3 cells attenuated cell proliferation (Fig. 5C). Results of the in vitro Matrigel invasion assays indicated that the invasive ability of mock-transfected PC-3 cells was $\sim 1 \cdot 4$-fold higher than that of GDF15 knocked down cells (Fig. 5D).

In order to further determine the correlation between the expressions of IL6 and GDF15, we cloned two subculture cell lines, namely LNCaP cells that overexpressed IL6 (LN-IL6) and IL6-knockdown PC-3 cells (PC-IL6si), as described in Materials and methods section. The expression levels of IL6 in the LN-IL6 cells (Fig. 6A), in the PC-IL6si cells (Fig. 6B), and in the mock-transfected cells (LN-DNA and PC-COLsi) were determined by RT-PCR and ELISA. Immunoblot assays indicated that levels of GDF15 in LN-IL6 cells were $1 \cdot 8$-fold higher than that of GDF15 in LN-DNA cells (Fig. 6C) and that levels of GDF15 in PC-IL6si cells were $31 \%$ lower than that of GDF15 in the PC-COLsi cells (Fig. 6D). The ELISA results demonstrated similar findings, namely that overexpression of IL6 led to an increase in GDF15 expression in LNCaP cells (Fig. 6E) and that expression of GDF15 protein was blocked in PC-3 cells when IL6 was knocked down (Fig. 6F). Interestingly, immunoblot assays revealed that knockdown IL6 in PC-3 cells blocked matriptase but enhanced maspin and NDRG1 gene expression (Fig. 6G).

We also evaluated the effect of recombinant human GDF15 on the cell proliferation of PC-3 and LNCaP cells. The ${ }^{3} \mathrm{H}$-thymidine incorporation assays indicated that GDF15 treatment enhanced the proliferation of PC-3 cells; however, GDF15 decreased the proliferation of LNCaP cells after $48 \mathrm{~h}$ of incubation (Fig. 7A). The ELISA results also indicated that GDF15 treatment for $24 \mathrm{~h}$ induced IL6 secretion in a dose-dependent manner (Fig. 7B). Results of immunoblot assays revealed that GDF15 treatment enhanced NDRG1 and

Figure 3 Stable overexpression of GDF15 enhances cell invasiveness and tumorigenesis of PC- 3 cells. (A) The invasive ability of cells was determined by the in vitro Matrigel invasion assay. Data are presented as the mean percentage ( \pm S.E.M.) of the OD in relation to that of the PCDNA cell group. (B) In vitro tumorigenesis of PCDNA and PCGDF15-2 cells was determined by soft agar assays. Cells were grown in $0.4 \%$ soft agar for 3 weeks, stained with p-iodonitrotetrazolium violet solution, and then photographed. The cells were counted and the results are represented graphically. (C) Nude mice were inoculated subcutaneously with PCDNA (white circle) or PCGDF15-2 (black circle) cells. During the indicated days, tumor size was measured with vernier calipers. Data are presented as tumor size in $\mathrm{mm}^{3}$ ( \pm S.E.M.) of inoculated cells measured at indicated time intervals. Blood samples were collected from experimental animals by cardiocentesis immediately after killing and were assayed for GDF15 (D) levels by ELISA. Data are presented as mean $( \pm$ S.E.M.; $n=6)$ of the GDF15 levels $\left({ }^{*} P<0.01\right)$. 

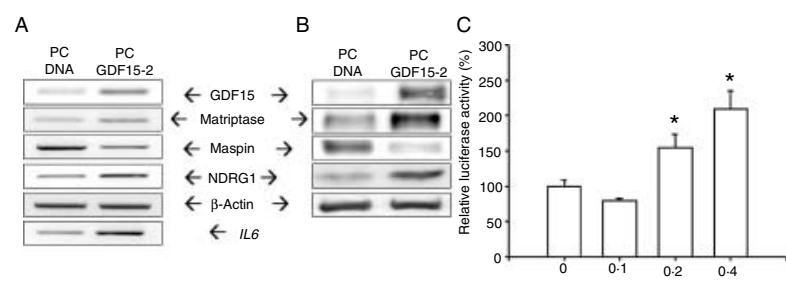

D

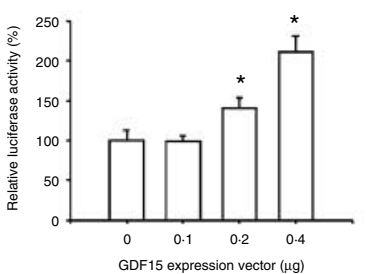

E
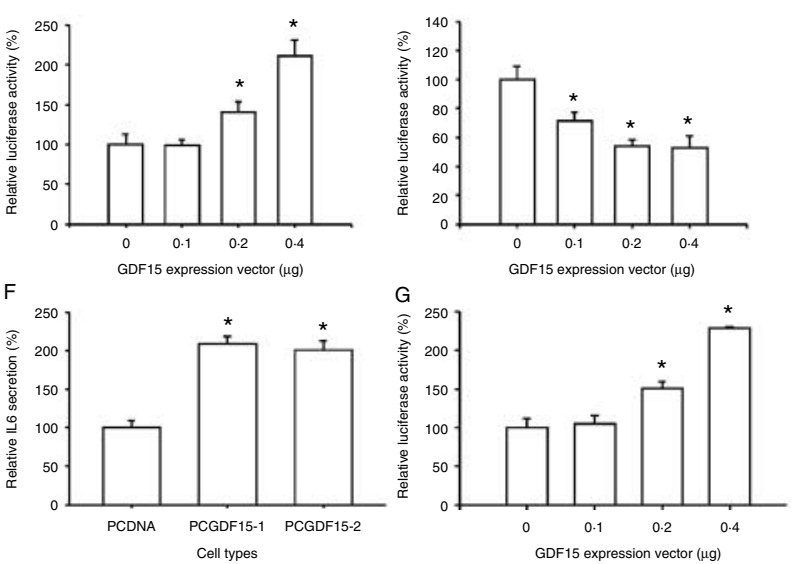

Figure 4 Stable overexpression of GDF15 modulates matriptase, maspin, NDRG1, and IL6 gene expression of PC-3 cells. The differences in gene expression (IL6, interleukin-6; NDRG1, N-myc downstream-regulated 1) between mock-transfected control cells (PCDNA) and GDF15 expression vector-transfected cells (PCGDF15-2) were determined by RT-PCR (A) and immunoblot assays (B). The matriptase promoter-luciferase reporter vector (C), NDRG1 promoter-luciferase reporter vector (D), or maspin promoter-luciferase reporter vector $(E)$ was cotransfected with different concentrations of GDF15 expression vector into PC-3 cells for $48 \mathrm{~h}$. Cells were lysed for the luciferase assays. Data are expressed as mean percentage \pm S.E.M. $(n=6)$. $(\mathrm{F})$ The PCDNA, PCGDF15-1, and PCGDF15-2 cells were cultured for $48 \mathrm{~h}$. Conditional media were collected for ELISA determination of IL6 levels. Data are presented as mean ( \pm s.E.M.) of the IL6 levels. (G) IL6 reporter vector-transfected PC-3 cells were cotransfected with different concentrations of GDF15 expression vector for $48 \mathrm{~h}$. Cells were lysed for the luciferase assays. Data are expressed as mean percentage \pm S.E.M. $\left(n=6 ;{ }^{\star} P<0.01\right)$.

matriptase protein expression but blocked maspin protein expression (Fig. 7C). The immunoblot assays indicated that doxorubicin treatment not only induced p53 expression but also enhanced GDF15 gene expression in LNCaP cells (Fig. 7D, top). The ELISA results also showed that doxorubicin treatment for $24 \mathrm{~h}$ induced GDF15 secretion in a dose-dependent manner (Fig. 7D, bottom).

\section{Discussion}

GDF15 has divergent effects and pleiotropic functions in cancer and might contribute to the proliferation, migration, invasion, metastasis, and treatment resistance of cancer cells as well as tumor-induced anorexia and weight loss in the late stages of cancer (Mimeault \& Batra 2010). In vitro and in vivo studies have shown that the involvement of GDF15 in cell growth inhibition, apoptosis induction, and enhancement of cancer invasiveness is dependent on cancer cell types (Liu et al. 2003, Lambert et al. 2006, Golkar et al. 2007).

The effect of GDF15 on cell proliferation in prostate carcinoma cells was inconclusive in previous studies. Studies of upregulation of GDF15 by vitamin $\mathrm{D}_{3}$ or isochaihulactone suggested cell growth suppression in prostate carcinoma LNCaP cells (Lambert et al. 2006, Chiu et al. 2011). However, a recent study indicated that a low dose of GDF15 $(\leq 0 \cdot 1 \mu \mathrm{g} / \mathrm{ml})$ did not affect cell proliferation but attenuated cell invasion of PC-3 cells (Cheng et al. 2011). For comparison, we treated PC-3 cells with a higher concentration $(0 \cdot 2-0 \cdot 8 \mu \mathrm{g} / \mathrm{ml})$ of GDF15 in this study, which showed that GDF15 did enhance cell proliferation. Moreover, our results also demonstrated that exogenous GDF15 divergently interfered with the cell proliferation of p53 WT LNCaP cells and p53-null PC-3 cells, suggesting that
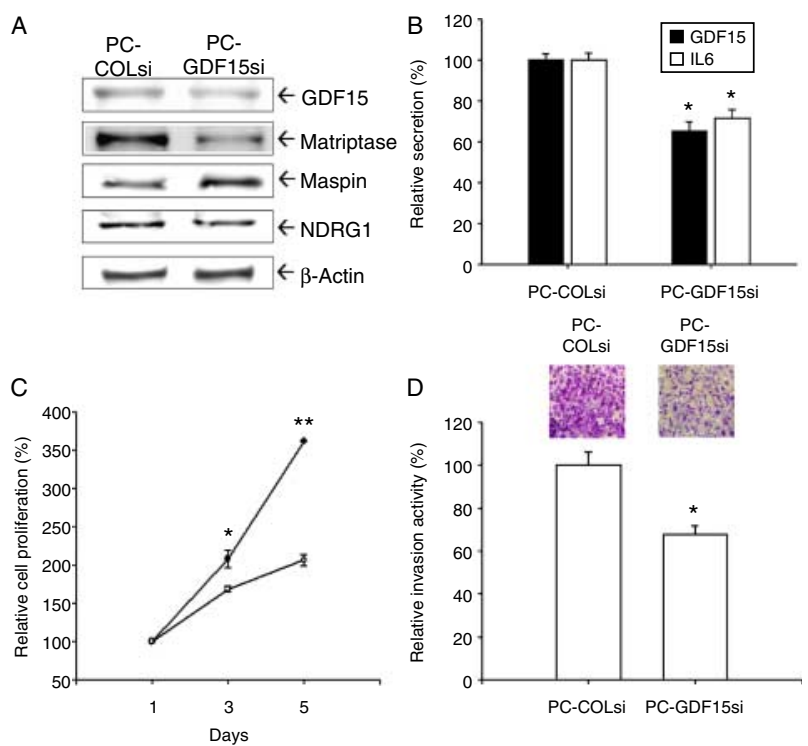

Figure 5 GDF15 knockdown attenuates cell proliferation and cell invasiveness of PC-3 cells. (A) The differences in protein expression of GDF15, maspin, and NDRG1 between mocktransfected control cells (PC-COLsi) and GDF15 siRNA-transfected cells (PC-GDF15si) were determined by immunoblot assays. (B). Conditional media were collected for ELISA determination of GDF15 and IL6 secretion. (C) Cell proliferation of mock-transfected PC-3 cells (PC-COLsi; black circle) and of GDF15 siRNA-transfected PC-3 cells (PC-GDF15si, white circle) was determined by ${ }^{3} \mathrm{H}$-thymidine incorporation. Each point on the curve represents the mean percentage \pm S.E.M. $(n=6)$ of that on day 1. (D) The invasive ability of cells was determined by the in vitro Matrigel invasion assay. Data are presented as the mean percentage ( \pm S.E.M.) of the OD in relation to that of the PC-COLsi cell group $\left({ }^{\star} P<0.05,{ }^{* *} P<0 \cdot 01\right)$. Full colour version of this figure available via http://dx.doi.org/10.1530/JME-11-0149. 

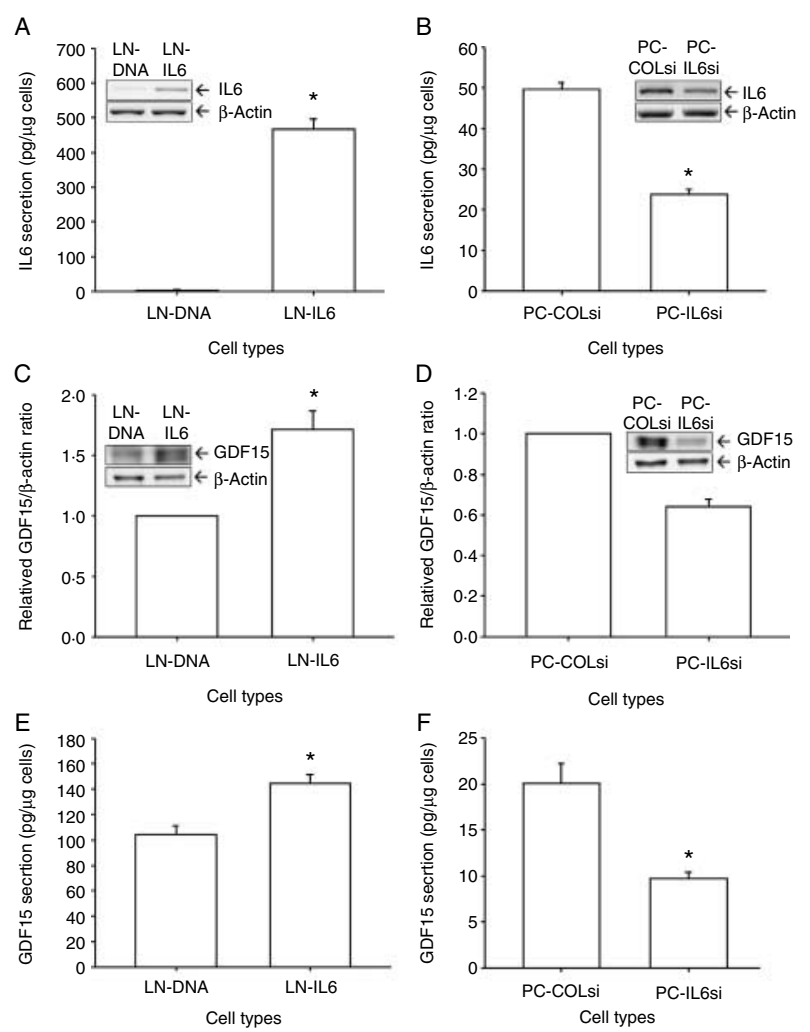

G

$$
\begin{aligned}
& \text { PC- PC- } \\
& \text { COLsi IL6si } \leftarrow \text { NDRG1 } \\
& \longrightarrow \leftarrow \text { NDRG } \\
& \sim \leftarrow \text { Matriptase } \\
& -\ldots \beta \text {-Actin }
\end{aligned}
$$

Figure 6 Expression of GDF15 is upregulated by IL6 in prostate carcinoma cells. Expression levels of the IL 6 gene in mocktransfected LNCaP cells (LN-DNA), IL6-transfected LNCaP cells (LN-IL6) (A), mock knockdown PC-3 cells (PC-COLsi), and IL6 knockdown PC-3 cells (PC-IL6si) (B) were determined by RT-PCR (top) and ELISA (bottom). Data are presented as mean ( \pm s.E.M.) of the IL6 levels. Expression levels of the GDF15gene in LN-IL6 cells (C) and PC-IL6si cells (D) in relation to their mocktransfected cells (LN-DNA and PC-COLsi) were determined by immunoblot assays. The intensities of the different bands were analyzed using the ChemiGenius-associated GeneTools program (Syngene). The quantitative analysis was done by determining the intensity of target genes and $\beta$-actin in each band from three independent experiments. Data are presented as the fold-induction of the relative density of the target gene/ $\beta$-actin ( \pm S.E.M.) in relation to the mock-transfected cells. ELISA was used to determine the expression of the GDF15 levels in LN-IL6 (E), PC-IL6si (F) cells, and in the mock-transfected cells (LN-DNA and PC-COLsi). Data are presented as mean ( \pm s.E.M.; $n=6$ ) of the GDF15 levels $\left({ }^{*} P<0 \cdot 01\right)$. (G) Expressions of NDRG1, maspin, matriptase, and $\beta$-actin in mock knockdown PC-3 cells (PC-COLsi), and IL6-knockdown PC-3 cells (PC-IL6si) were determined by immunoblotting assay.

the effects of GDF15 on prostate carcinoma cells may depend on both the GDF15 levels and the cell types.

Several clinical studies have also demonstrated that enhancement of GDF15 expression is positively correlated with poor prognosis and patient survival rates
(Welsh et al. 2003, Brown et al. 2009). Results of this study indicate that stable overexpression of GDF15 in PC-3 cells affects cell proliferation and colony formation in soft agar, suggesting that GDF15 induces tumorigenic activity in prostate carcinoma cells. Our results indicated that GDF15 overexpression enhanced the invasive and metastatic properties of prostate carcinoma PC-3 cells while knockdown GDF15 attenuated cell motility, which is consistent with findings reported by Senapati et al. (2010). However, in a study by Cheng et al. (2011), it is shown that cell motility did not significantly enhance when GDF15 was transiently knocked down in PC-3 cells, although exogenous GDF15 treatments $(0 \cdot 02-0 \cdot 1 \mu \mathrm{g} / \mathrm{ml})$ did significantly block the invasive ability of PC-3 cells.

Studies have shown that GDF15 gene expression is controlled by multiple factors, such as p53, vitamin $\mathrm{D}_{3}$, TNF, Sp1, and Egr-1 (Shim \& Eling 2005, Lambert et al. 2006, Zimmers et al. 2006). We used doxorubicintreated LNCaP cells, which expressed wild-type p53

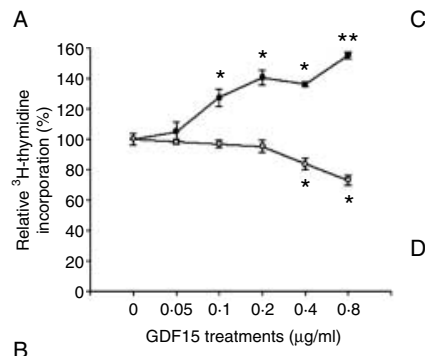

C
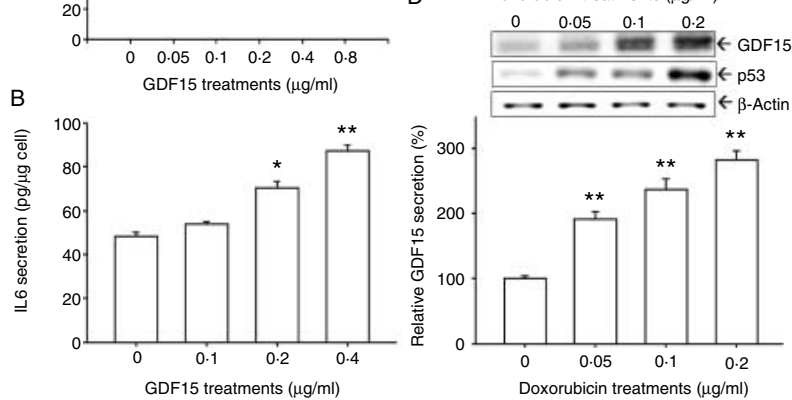

Figure 7 Divergent effect of GDF15 on cell proliferation in prostate carcinoma cells. (A) LNCaP (white circle) and PC-3 (black circle) cells were treated with various concentrations of recombinant human GDF15 as indicated for $48 \mathrm{~h}$. Cell proliferation was determined by ${ }^{3} \mathrm{H}$-thymidine incorporation. Each point on the curve represents the mean percentage \pm S.E.M. $(n=6)$ of that of control group. (B) The PC-3 cells were cultured with various concentrations of recombinant human GDF15 as indicated for $48 \mathrm{~h}$. Conditional media were collected for ELISA determination of IL6 levels. Data are presented as mean ( \pm S.E.M.) of the IL6 levels. (C) The PC-3 cells were cultured with various concentrations of recombinant human GDF15 as indicated for $24 \mathrm{~h}$. Cell extracts were used in the immunoblot assays for determination of NDRG1, matriptase, and maspin expressions. (D) The LNCaP cells were cultured with various concentrations of doxorubicin as indicated for $24 \mathrm{~h}$. Cell extracts were used in the immunoblot assays for determination of GDF15 and p53 expressions (top) and the conditional media were collected for ELISA determination of GDF15 levels (bottom). Data are expressed as mean percent ( \pm S.E.M.) of the IL6 levels to that of the control group $\left({ }^{\star} P<0.05,{ }^{\star \star} P<0.01\right)$. 
(Tsui et al. 2004), indicating that p53 upregulates GDF15 expression in LNCaP cells. Similar results have been found in a previous study, which indicated that ectopic expression p53 induced GDF15 expression in PC3 and ALVA-3 PCa cells (Lambert et al. 2006, Cheng et al. 2011).

The mechanisms governing the effect of GDF15 on the expression of other genes are still not well known. Iczkowski \& Pantazis (2003) suggested that TGF- $\beta$ RII is likely to form part of the complex where GDF15 exerts its effect on body weight through the regulation of the neuropeptide $\mathrm{Y}(N F Y)$ gene and the pro-opiomelanocortin $(P O M C)$ gene in the mouse hypothalamus. An in vitro study found that GDF15 induces apoptosis by blocking expression of metallothionein $1 \mathrm{E}$, RhoE, and catenin $\delta 1$ genes (Liu et al. 2003), and the xenograft animal study indicated that GDF15 inhibits tumorigenesis by suppressing insulin-like growth factor-1 and cyclin D1 of DU145 cells (Wang et al. 2012). Chiu et al. (2011) suggested that isochaihulactone induces the expression of GDF15 via JNK activation in LNCaP cells. A recent study showed that overexpression of GDF15 induces metastasis of human prostate cancer cells through a FAK-RhoA signaling pathway (Senapati et al. 2010). This study is the first to report the dysregulation of IL6, matriptase, maspin, and NDRG1 expression by GDF15 in PC-3 cells.

Matriptase is an epithelium-derived type II transmembrane serine protease that has been implicated in activating substrates such as pro-hepatocyte growth factor and pro-urokinase plasminogen activator (Lin et al. 1999, Wu et al. 2010). Inhibition of endogenous matriptase synthesis or treatment of cells with matriptase inhibitors has been shown to reduce invasion of prostate carcinoma cells, suggesting that matriptase plays a role in the properties of the invasive phenotype (Forbs et al. 2005, Sanders et al. 2006, Tsui et al. 2008a). In this study, we found that overexpression of GDF15 resulted in increased matriptase expression in vitro, which may account for the increasing invasiveness of PC-3 cells with forced overexpression of GDF15.

Maspin, a member of the serine protease inhibitor family, has been demonstrated to induce a more prominent actin cytoskeleton, to reduce invasion capacity, to increase the rate of spontaneous apoptosis, and to alter proteasome function in maspin-expressing cells (Li et al. 2007). In prostate cancer, maspin inhibits tumor growth, reduces bone metastasis, and decreases angiogenesis in vitro and in vivo (Chen et al. 2003, Watanabe et al. 2005, Hall et al. 2008). We found that PC-3 cells engineered to overexpress GDF15 blocked maspin gene expression. This finding might explain, in part, how overexpression of GDF15 leads to an increased proliferation and invasiveness of prostate carcinoma cells by GDF15.
NDRG1 is known to play important roles in both androgen-induced cell differentiation and inhibition of prostate metastasis (Mostaghel et al. 2007, Tu et al. 2007, Chung et al. 2012). The expression of NDRG1 was shown to be inversely correlated with Gleason score and overall survival rate in patients with prostate cancer (Bandyopadhyay et al. 2003, Song et al. 2010). Interestingly, results of this study indicated that GDF15 upregulates $N D R G 1$ gene expression, while knockdown of GDF15 downregulates NDRG1 protein expression in PC-3 cells. The mechanisms and physiological function governing the upregulation of NDRG1 by GDF15 in PC3 cells are still unknown. As results of this study indicated that GDF15 treatment enhanced proliferation of PC-3 cells but attenuated proliferation of LNCaP cells, therefore, the upregulation of NDRG1 by GDF15 may explain the divergent effects of GDF15related proliferation and invasion of different types of cancer cells (Mimeault \& Batra 2010).

IL6 is a multifunctional cytokine, and an activator of androgen receptor in prostate cancer may yield either tumor cell proliferation or differentiation. Prolonged treatment with IL6 results in generations of sublines that express a more malignant prostate phenotype (Culig 2011). Previous studies have shown that plasma IL6 levels have prognostic significance in patients with metastatic hormone-refractory prostate cancer (George et al. 2005). An increase in serum cytokines including IL6 was found in cachectic patients with prostate carcinoma, and immunostaining levels of IL6 and its receptor increased with Gleason score (Pfitzenmaier et al. 2003, Royuela et al. 2004). In vitro studies have also indicated that IL6 enhanced the expression of prostatespecific antigen, a tumor marker of prostate cancer, in LNCaP cells (Tsui et al. 2011b). Results from in vitro studies have shown that both IL6 and IL6 receptors are expressed and that IL6 should be considered a positive growth factor in PC-3 cells (Selander et al. 2006, Tsui et al. 2008b). In this study, we found that IL6 was upregulated in PC-3 cells that have been engineered to overexpress GDF15; moreover, IL6 secretion was blocked when GDF15 was knocked down in PC-3 cells. It seems that the expression of GDF15 and that of IL6 are regulated by a positive feedback loop in prostate carcinoma cells. Our results indicated that IL6 and GDF15 have similar effects on the gene expression of matriptase and maspin. However, our results also showed that the expression of NDRG1 protein was enhanced in PC-3 cells while IL6 was knocked down, suggesting that GDF15 and IL6 may also regulate target genes in a divergent way. Further studies are warranted to investigate the mechanisms governing the effects of IL6 on GDF15 expression.

In conclusion, we have demonstrated that overexpression of GDF15 increases cell proliferation, tumorigenesis, and invasiveness of PC-3 cells. The 
tumor-inductive effects of GDF15 on prostate carcinoma cells may be caused by the dysregulation of gene expression of maspin, matriptase, and IL6. The regulatory mechanisms governing the expression of GDF15 and IL6 are regulated by a positive feedback loop in prostate carcinoma cells.

\section{Declaration of interest}

The authors declare that there is no conflict of interest that would prejudice the impartiality of the research reported.

\section{Funding}

This Research was supported by Chang Gung Memorial Hospital (CMRP-D190542, -D190612, and -G392142) and Taiwan National Science Council (101-2314-B-182A-099-MY3 and NSC 101-2320-B182-002).

\section{References}

Baek SJ, Okazaki R, Lee SH, Martinez J, Kim JS, Yamaguchi K, Mishina Y, Martin DW, Shoieb A, McEntee MF et al. 2006 Nonsteroidal anti-inflammatory drug-activated gene-1 over expression in transgenic mice suppresses intestinal neoplasia. Gastroenterology 131 1553-1560. (doi:10.1053/j.gastro.2006.09.015)

Baek KE, Yoon SR, Kim JT, Kim KS, Kang SH, Yang Y, Lim JS, Choi I, Nam MS, Yoon NM et al. 2009 Upregulation and secretion of macrophage inhibitory cytokine-1 (MIC-1) in gastric cancer. Clinica Chimica Acta 401 128-133. (doi:10.1016/j.cca.2008.12.008)

Bandyopadhyay S, Pai SK, Gross SC, Hirota S, Hosobe S, Miura K, Saito K, Commes T, Hayashi S, Watabe M et al. 2003 The Drg-1 gene suppresses tumor metastasis in prostate cancer. Cancer Research 63 1731-1736.

Bauskin AR, Brown DA, Junankar S, Rasiah KK, Eggleton S, Hunter M, Liu T, Smith D, Kuffner T, Pankhurst GJ et al. 2005 The propeptide mediates formation of stromal stores of PROMIC-1: role in determining prostate cancer outcome. Cancer Research $\mathbf{6 5}$ 2330-2336. (doi:10.1158/0008-5472.CAN-04-3827)

Bootcov MR, Bauskin AR, Valenzuela SM, Moore AG, Bansal M, He XY, Zhang HP, Donnellan M, Mahler S, Pryor K et al. 1997 MIC-1, a novel macrophage inhibitory cytokine, is a divergent member of the TGF- $\beta$ superfamily. PNAS 94 11514-11519. (doi:10.1073/pnas.94. 21.11514)

Brown DA, Lindmark F, Stattin P, Balter K, Adami HO, Zheng SL, Xu J, Isaacs WB, Gronberg H, Breit SN et al. 2009 Macrophage inhibitory cytokine 1: a new prognostic marker in prostate cancer. Clinical Cancer Research 15 6658-6664. (doi:10.1158/1078-0432.CCR-083126)

Chen ML, Biliran HR, Bhagat S, Menckett J, Abrams J, Fridman R, Zachareas M \& Sheng S 2003 Maspin expression inhibits oesteolysis, tumor growth, and angiogenesis in a model of prostate cancer bone metastasis. PNAS 100 7847-7852. (doi:10.1073/pnas.1331360100)

Cheng JC, Chang HM \& Leung PC 2011 Wild-type p53 attenuates cancer cell motility by inducing growth differentiation factor-15 expression. Endocrinology 152 2987-2995. (doi:10.1210/en.20110059)

Chiu SC, Wang MJ, Yang HH, Chen SP, Huang SY, Chen YL, Lin SZ, Harn HJ \& Pang CY 2011 Activation of NAG-1 via JNK signaling revealed an isochaihulactone-triggered cell death in human $\mathrm{LNCaP}$ prostate cancer cells. BMC Cancer 11 146. (doi:10.1186/1471-2407$11-146)$
Chung LC, Tsui KH, Feng TH, Lee SL, Chang PL \& Juang HH 2011 Curcumin provides potential protection against the activation of hypoxia and prolyl 4-hydroxylase inhibitors on prostate-specific antigen expression in human prostate carcinoma cells. Molecular Nutrition and Food Research 55 16666-16676. (doi:10.1002/mnfr. 201100328)

Chung LC, Tsui KH, Feng TH, Lee SL, Chang PL \& Juang HH 2012 L-mimosine blocks cell proliferation via upregulation of B-cell translocation gene 2 and $\mathrm{N}$-myc downstream regulated gene 1 in prostate carcinoma cells. American Journal of Physiology. Cell Physiology 302 C676-C685. (doi:10.1152/ajpcell.00180.2011)

Culig Z 2011 Cytokine disbalance in common human cancers. Biochimica et Biophysica Acta 1813 308-314. (doi:10.1016/j.bbamcr. 2010.12.010)

Forbs D, Thiel S, Stella MC, Sturzebecher A, Schweinitz A, Steinmetzer T, Sturzebecher J \& Uhland K 2005 In vitro inhibition of matriptase prevents invasive growth of cell lines of prostate and colon carcinoma. International Journal of Oncology 27 1061-1070.

George DJ, Halabi S, Shepard TF, Sanford B, Vogelzang NJ, Small EJ \& Kantoff PW 2005 The prognostic significance of plasma interleukin-6 levels in patients with metastatic hormone-refractory prostate cancer: results from cancer and leukemia group B 9480. Clinical Cancer Research 11 1815-1820. (doi:10.1158/1078-0432.CCR-04-1560)

Golkar L, Ding XZ, Ujiki MB, Salabat MR, Kelly DL, Scholtens D, Fought AJ, Bentrem DJ, Talamonti MS, Bell RH et al. 2007 Resveratrol inhibits pancreatic cancer cell proliferation through transcriptional induction of macrophage inhibitory cytokine-1. Journal of Surgical Research 138 163-169. (doi:10.1016/j.jss.2006.05.037)

Hall DC, Johnson-Pais TL, Grubbs B, Bernal R, Leach RJ \& Padalecki SS 2008 Maspin reduces prostate cancer metastasis to bone. Urologic Oncology 26 652-658. (doi:10.1016/j.urolonc. 2007.07.017)

Hromas R, Hufford M, Sutton J, Xu D, Li Y \& Lu L 1997 PLAB, a novel placental bone morphogenetic protein. Biochimica et Biophysica Acta 1354 40-44. (doi:10.1016/S0167-4781(97)00122-X)

Iczkowski KA \& Pantazis CG 2003 Overexpression of NSAID-activated gene product in prostate cancer. International Journal of Surgical Pathology 11 159-166. (doi:10.1177/106689690301100302)

Johnen H, Lin S, Kuffner T, Brown D, Tsai VWW, Bauskin AR, Wu L, Pankhurst G, Jiang L, Junankar S et al. 2007 Tumor-induced anorexia and weight loss are mediated by the TGF- $\beta$ superfamily cytokine MIC-1. Nature Medicine 13 1333-1340. (doi:10.1038/ nm1677)

Kadara H, Schroeder CP, Lotan D, Pisano C \& Lotan R 2006 Induction of GDF-15/NAG-1/MIC-1 in human lung carcinoma cells by retinoid-related molecules and assessment of its role in apoptosis. Cancer Biology E Therapy 5 518-522. (doi:10.4161/cbt.5.5.2602)

Karan D, Chen SJ, Johansson SL, Singh AP, Paralkar VM, Lin MF \& Batra SK 2003 Dysregulated expression of MIC-1/PDF in human prostate tumor cells. Biochemical and Biophysical Research Communications 305 598-604. (doi:10.1016/S0006-291X(03)00823-4)

Kawahara T, Ishiguro H, Hoshino K, Teranishi J, Miyoshi Y, Kubota Y \& Uemura H 2010 Analysis of NSAID-activated gene 1 expression in prostate cancer. Urologia Internationalis 84 198-202. (doi:10.1159/ 000277599)

Lambert JR, Kelly JA, Shim M, Huffer WE, Nordeen SK, Baek SJ, Eling TE \& Lucia S 2006 Prostate derived factor in human prostate cancer cells: gene induction by vitamin $\mathrm{D}$ via a p53-dependent mechanism and inhibition of prostate cancer cell growth. Journal of Cellular Physiology 208 566-574. (doi:10.1002/jcp.20692)

Li X, Chen D, Ying S, Meng Y, Yang H, Landis-Piwowar KR, Li Y, Sarkar FH, Reddy GP, Dou QP et al. 2007 Maspin augments proteasome inhibitor-induced apoptosis in prostate cancer cells. Journal of Cellular Physiology 212 298-306. (doi:10.1002/jcp.21102)

Lin CY, Anders J, Johnson M, Sang QA \& Dickson RB 1999 Molecular cloning of cDNA for matriptase, a matrix-degrading serine protease with trypsin-like activity. Journal of Biological Chemistry 274 18231-18236. (doi:10.1074/jbc.274.26.18231) 
Liu T, Bauskin AR, Zaunders J, Brown DA, Pankurst S, Russell PJ \& Breit SN 2003 Macrophage inhibitory cytokine 1 reduces cell adhesion and induces apoptosis in prostate cancer cells. Cancer Research 63 5034-5040.

Mimeault M \& Batra SK 2010 Divergent molecular mechanisms underlying the pleiotropic functions of macrophage inhibitory cytokine-1 in cancer. Journal of Cellular Physiology 224 626-635. (doi:10.1002/jcp.22196)

Mostaghel EA, Page ST, Lin DW, Fazli L, Coleman IM, True LD, Knudsen B, Hess DL, Nelson CC, Matsumoto AM et al. 2007 Intraprostatic androgens and androgen-regulated gene expression persist after testosterone suppression: therapeutic implications for castration-resistant prostate cancer. Cancer Research 67 5033-5041. (doi:10.1158/0008-5472.CAN-06-3332)

Pang ST, Hsieh WC, Chuang CK, Chao CH, Weng WH \& Juang HH 2009 Thioredoxin-interacting protein: an oxidative stress-related gene is upregulated by glucose in human prostate carcinoma cells. Journal of Molecular Endocrinology 42 205-214. (doi:10.1677/ JME-08-0033)

Paralkar VM, Vail AL, Grasser WA, Brown TA, Xu H, Vukicevic S, Ke HZ, Zi H, Owen TA \& Thompson DD 1998 Cloning and characterization of a novel member of the transforming growth factor- $\beta$ /bone morphogenetic protein family. Journal of Biological Chemistry 273 13760-13767. (doi:10.1074/jbc.273.22.13760)

Pfitzenmaier J, Vessella R, Higano CS, Noteboom JL, Wallace D \& Corey E 2003 Elevation of cytokine levels in cachectic patients with prostate carcinoma. Cancer 97 1211-1216. (doi:10.1002/ cncr.11178)

Royuela M, Ricote M, Parsons MS, Garcia-Tunon I, Paniagua R \& de Miguel MP 2004 Immunohistochemical analysis of the IL-6 family of cytokines and their receptor in benign, hyperplasic and malignant human prostate. Journal of Pathology 202 41-49. (doi:10.1002/path.1476)

Sanders AJ, Parr C, Davies G, Martin TA, Lane J, Mason MD \& Jiang WG 2006 Genetic reduction of matriptase-1 expression is associated with a reduction in the aggressive phenotype of prostate cancer cells in vitro and in vivo. Journal of Experimental Therapeutics $\mathcal{E}$ Oncology 6 39-48.

Selander KS, Steiner H, Cavarretta IT, Moser PL, Berger AP, Bektic J, Dietrich H, Zaki MH, Nakada M, Hobisch A et al. 2006 Regulation of growth of prostate cancer cells selected in the presence of interleukin- 6 by the anti-interleukin- 6 antibody CNTO 328. Prostate 66 1744-1752. (doi:10.1002/pros.20492)

Senapati S, Rachagani S, Chaudhary K, Johansson SL, Singh RK \& Batra SK 2010 Overexpression of macrophage inhibitory cytokine-1 induces metastasis of human prostate cancer cells through the FAKRhoA signaling pathway. Oncogene 29 1293-1302. (doi:10.1038/onc. 2009.420)

Shim M \& Eling TE 2005 Protein kinase C-dependent regulation of NAG-1/placental bone morphogenic protein/MIC-1 expression in LNCaP prostate carcinoma cells. Journal of Biological Chemistry 280 18636-18642. (doi:10.1074/jbc.M414613200)

Song Y, Oda Y, Hori M, Kuroiwa K, Ono M, Hosoi F, Basaki Y, Tokunaga S, Kuwano M, Naito $\mathrm{S}$ et al. $2010 \mathrm{~N}$-myc downstream regulated gene-1/Cap43 may play an important role in malignant progression of prostate cancer, in its close association with E-cadherin. Human Pathology 41 214-222. (doi:10.1016/j.humpath.2009.07.011)

Tsui KH, Chang PL, Lin HT \& Juang HH 2004 Down-regulation of the prostate specific antigen promoter by $\mathrm{p} 53$ in human prostate cancer cells. Journal of Urology 172 2035-2039. (doi:10.1097/01.ju. 0000138053.78518.b2)

Tsui KH, Chang PL, Feng TH, Chung LC, Shu SY \& Juang HH $2008 a$ Down-regulation of matriptase by overexpression of bikunin attenuates cell invasion in prostate carcinoma cells. Anticancer Research 28 1977-1984.
Tsui KH, Feng TH, Hsieh WC, Chang PL \& Juang HH $2008 b$ Expression of interleukin-6 is downregulated by 17-(allylamino)-17-demethoxygeldanamycin in human prostatic carcinoma cells. Acta Pharmacologica Sinica 29 1334-1341. (doi:10. $1111 / \mathrm{j} .1745-7254.2008 .00887 . x)$

Tsui KH, Feng TH, Lin YF, Chang PL \& Juang HH $2011 a$ p53 downregulates the gene expression of mitochondrial aconitase in human prostate carcinoma cell. Prostate 71 62-70. (doi:10.1002/ pros.21222)

Tsui KH, Lin YF, Chen YH, Chang PL \& Juang HH $2011 b$ Mechanisms by which interleukin-6 regulates prostate specific antigen gene expression in prostate LNCaP carcinoma cells. Journal of Andrology 32 383-393. (doi:10.2164/jandrol.109.009878)

Tsui KH, Chung LC, Feng TH, Chang PL \& Juang HH $2012 a$ Upregulation of prostate-derived Ets factor by luteolin causes inhibition of cell proliferation and cell invasion in prostate carcinoma cells. International Journal of Cancer 130 2812-2823. (doi:10.1002/ijc.26284)

Tsui KH, Chung LC, Feng TH, Chang PL \& Juang HH $2012 b$ Glycoprotein transmembrane nmb: an androgen-downregulated gene attenuates cell invasion and tumorigenesis in prostate carcinoma cells. Prostate 72 1431-1442 (DOI: 10.1002/pros.22494). (doi:10.1002/pros.22494)

Tu LC, Yan X, Hood L \& Lin B 2007 Proteomics analysis of the interactome of $\mathrm{N}$-myc downstream regulated gene 1 and its interactions with the androgen response program in prostate cancer cells. Molecular $\mathcal{E}$ Cellular Proteomics 6 575-588. (doi:10.1074/mcp.M600249-MCP200)

Wakchoure S, Swain TM, Hentunen TA, Bauskin AR, Brown DA, Breit SN, Vuopala KS, Harris KW \& Selander KS 2009 Expression of macrophage inhibitory cytokine-1 in prostate cancer bone metastases induces osteoclast activation and weight loss. Prostate 69 652-661. (doi:10.1002/pros.20913)

Wang X, Chrysovergis K, Bienstock RJ, Shim M \& Eling TE 2012 The H6D variant of NAG-1/GDF15 inhibits prostate xenograft growth in vivo. Prostate 72 677-689. (doi:10.1002/pros.21471)

Watanabe M, Nasu Y, Kashiwakura Y, Kusumi N, Tamayose K, Nagai A, Sasano T, Shimasa T, Daida H \& Kumon H 2005 Adeno-associated virus 2-mediated intratumoral prostate cancer gene therapy: long-term maspin expression efficiently suppresses tumor growth. Human Gene Therapy 16 699-710. (doi:10.1089/hum.2005. 16.699)

Welsh JB, Sapinoso LM, Kern SG, Brown DA, Liu T, Bauskin AR, Ward RL, Hawkins NJ, Quinn DI, Russell PJ et al. 2003 Large-scale delineation of secreted protein biomarkers overexpressed in cancer tissue and serum. PNAS 100 3410-3415. (doi:10.1073/ pnas.0530278100)

Wu SR, Cheng TS, Chen WC, Shyu HY, Ko CJ, Huang HP, Teng CH, Lin CH, Johnson MD, Lin CY et al. 2010 Matriptase is involved in ErbB-2-induced prostate cancer cell invasion. American Journal of Pathology 177 3145-3158. (doi:10.2353/ajpath.2010. 100228)

Zimmers TA, Jin X, Hsiao EC, Perez EA, Pierce RH, Chavin KD \& Koniaris LG 2006 Growth differentiation factor-15: induction in liver injury through p53 and tumor necrosis factor-independent mechanisms. Journal of Surgical Research 130 45-51. (doi:10.1016/ j.jss.2005.07.036)

Received in final form 28 July 2012

Accepted 3 August 2012

Made available online as an Accepted Preprint 7 August 2012 